\title{
Two approaches to improve fertility of subclinical mastitic dairy cows
}

\author{
Y. Lavon, ${ }^{*}$ M. Kaim,† G. Leitner,‡ D. Biran,§ E. Ezra, ${ }^{*}$ and D. Wolfenson\#1 \\ *Israel Cattle Breeders Association, Caesarea 38900, Israel \\ †Institute of Animal Science, Agricultural Research Organization, Bet Dagan 50250, Israel \\ ¥Mastitis Laboratory, Veterinary Institute, Bet Dagan 50250, Israel \\ §Extension Services, Ministry of Agriculture, Bet Dagan 50250, Israel \\ \#Department of Animal Sciences, Faculty of Agriculture, Food and Environment, Hebrew University, Rehovot 76100, Israel
}

\begin{abstract}
Mastitis, particularly in its subclinical form, is a widely spread disease that reduces the fertility of lactating cows. A major cause of poor conception risk has been associated with delayed ovulation of a large subgroup of subclinical mastitic cows. This study examined 2 approaches to improve fertility in this subgroup. Subclinical mastitic cows were defined by somatic cell count elevated above a threshold of 150,000 cells/mL of milk determined in all monthly test day samples collected before AI. Uninfected (control) cows were defined by somatic cell count below threshold. In experiment 1 , we examined a hormonal approach aimed to correct the timing of ovulation in mastitic cows in which it would otherwise be delayed. The probability of conception of mastitic and uninfected groups following Ovsynch (OVS) and timed AI versus AI following detected estrus (E) was examined ( $\mathrm{n}=1,553$ AI) and analyzed by a multivariable, logistic model statement using the GLIMMIX procedure of SAS. The OVS protocol significantly elevated the probability of conception of mastitic cows to a level similar to that of their uninfected counterparts. Actual mean conception risks for uninfected-E, subclinical-E, uninfected-OVS, and subclinical-OVS groups were 41.8, 26.4, 39.3, and $40.5 \%$, respectively. The OVS protocol did not improve probability of conception in cows diagnosed with uterine disease postpartum. In experiment 2, a management approach aimed to better synchronize timing of ovulation with timing of $\mathrm{AI}$ in subclinical mastitic cows was examined. A second AI was added $24 \mathrm{~h}$ after the first (routine) AI, following detection of natural estrus. Probability of conception did not differ between subclinical mastitic cows inseminated once or twice. Lack of improvement in conception risk might be related to low preovulatory LH surge in mastitic cows, which is
\end{abstract}

Received April 25, 2015.

Accepted November 21, 2015.

${ }^{1}$ Corresponding author: david.wolfenson@mail.huji.ac.il likely to induce not only delayed ovulation but also disruption of oocyte maturation. Thus the OVS protocol can improve fertility of subclinical mastitic cows, probably due to "corrected" timing of ovulation in cows in which it would otherwise be delayed.

Key words: subclinical mastitis, fertility, Ovsynch protocol, delayed ovulation

\section{INTRODUCTION}

Mastitis is a major disease that causes economic losses to the dairy industry. These losses have been related to decreased milk yield and quality, and increased veterinary services and culling rate, among others (Losinger, 2005; Halasa et al., 2007). During the last decade, however, an association between decreased fertility and clinical and subclinical mastitis has been recognized (Schrick et al., 2001; Santos et al., 2004; Hertl et al., 2010), causing significant disruption of reproductive performance associated with additional loss to dairy farms. In a large epidemiological study of 287,000 AI cows, we showed a significant decrease in the probability of conception in likely subclinical mastitic cows exhibiting chronic elevation of SCC $>150,000$ cells $/ \mathrm{mL}$ of milk (Lavon et al., 2011a). Similar findings showing an association between subclinical mastitis and poor conception were then also reported by Hudson et al. (2012). The fact that between 20 and $40 \%$ of cows in commercial dairy herds in several countries have subclinical, long-term, chronic mastitis (Ramírez et al., 2014) emphasizes the importance of studying approaches to improve fertility of subclinical mastitic cows.

Unlike clinical infection and its effects on reproduction, which have been studied quite intensively over the years, the mechanism of subclinical mastitis-induced disruption of fertility is poorly documented. Recent studies have shed some light on this issue. It was found that about $30 \%$ of naturally occurring subclinical mastitic cows manifest delayed ovulation (Lavon et al., 2010). An estrus-to-ovulation interval of $56 \mathrm{~h}$ on 
average was recorded, compared with a normal interval of $28 \mathrm{~h}$ in uninfected cows and the remaining, nonsusceptible, $70 \%$ of mastitic cows. Delayed ovulation could interfere with the process of fertilization, subsequently leading to poor conception risk $(\mathbf{C R}$; no. of pregnancies per no. of inseminations). In a follow-up study, a similar proportion (one-third) of subclinical cows exhibited reduced estradiol and androstenedione concentrations in the follicular fluid of preovulatory follicles (Lavon et al., 2011b). The latter was associated with reduced mRNA expression of major steroidogenic genes in both theca and granulosa cells (Lavon et al., 2011b). Induction of subclinical mastitis showed a proportion of cows $(40 \%)$ quite similar to that found in naturally occurring mastitic cows that exhibited reduced follicular estradiol concentrations (Furman et al., 2014).

To the best of our knowledge, studies to improve fertility of mastitic cows, particularly those with widely spread subclinical mastitis, have never been attempted. Based on above studies, improved fertility might be achievable for cows with mastitis-induced delayed ovulation. Better synchronization of the timing of ovulation relative to AI, using a hormonal or management approach, could improve fertilization rate. The objective was to improve conception of subclinical mastitic cows by using the Ovsynch protocol, which induces a normal LH surge at the optimal time relative to timed AI (hormonal approach; experiment 1), or by adding a second AI $24 \mathrm{~h}$ after the first, regular AI, to better suit the delayed timing of ovulation (management approach; experiment 2).

\section{MATERIALS AND METHODS}

Two independent fertility studies were performed. The experiments were conducted according to the guidelines of the animal care and welfare committee of the Hebrew University.

\section{Experiment 1: Study Design for the Hormonal Approach}

Data were collected from 3 commercial herds during 2 periods from 2003 through 2007 (early) and from 2009 through 2011 (late). Overall, 1,553 AI of primiparous and multiparous Holstein cows were included. The SCC analyzed from the monthly milk-test samples at the central laboratories of the Israeli Cattle Breeders Association were used as an indication of mastitis. Composite milk samples were obtained by technicians, preserved by the addition of Bronopol (Advanced Instruments, Norwood, MA) and analyzed in a Milkoscan with Fossomatic Analyzer (Foss Electric, Hillerød, Denmark) for SCC. A SCC threshold of 150,000 cells/
$\mathrm{mL}$ of milk was set to distinguish between uninfected and infected cows, as previously described (Lavon et al., 2011a). This cutoff was based on a meta-analysis of 21 published studies conducted in different countries (Djabri et al., 2002). Cows with 2 or 3 (depending on duration of calving to first AI interval) monthly milk tests before first AI (first postpartum milk test collected excluded) with SCC elevated above the cutoff line, in all samples collected, were considered to be subclinical mastitic cows (Lavon et al., 2011a). Cows with all samples below 150,000 cells/mL of milk were considered to be uninfected, and those with mixed values (above and below the cutoff) were not included in the study. In the early period of the study, cows were classified as uninfected or with subclinical inflammation retrospectively according to SCC profile. In the late period, SCC information was available online from the Israeli Cattle Breeders Association central laboratories and cows were assigned to uninfected or infected subgroups close to expected date of AI. Cows in each classification were assigned randomly to either AI following detection of estrus (E) or timed AI following the Ovsynch (OVS) protocol. The OVS protocol consisted of first GnRH injection $(200 \mu \mathrm{g}$ of Gonadorelin i.m., Gonabreed, Parnell Laboratories, Alexandria, Australia) followed by $\mathrm{PGF}_{2 \alpha}$ $7 \mathrm{~d}$ later $(500 \mu \mathrm{g}$ of Cloprostenol, Estroplan, Parnell Laboratories) and a second GnRH injection $60 \mathrm{~h}$ later, and timed AI $16 \mathrm{~h}$ after GnRH. A small proportion of cows that were detected in estrus and inseminated before the scheduled timed AI were excluded from the analysis. Detection of estrus occurred trice daily before milking by a computerized pedometric system (Afimilk, Afikim, Israel). Pregnancy was confirmed by uterine palpation per rectum 40 to $50 \mathrm{~d}$ after AI. Cows that manifested estrus before being checked for pregnancy and those that were not diagnosed as pregnant were recorded as nonpregnant.

A total of 1,165 uninfected and 388 subclinical mastitic cows were included in the study. Accordingly, 4 experimental groups were evaluated: uninfected-E (n $=593)$, uninfected-OVS $(\mathrm{n}=572)$, subclinical-E $(\mathrm{n}=$ 193), and subclinical-OVS $(\mathrm{n}=195)$; the subclinical mastitic group contained $25 \%$ of all experimental cows. Cows in the E and OVS groups were assigned alternately to their experimental groups in all herds during early and later periods of the study. Also recorded in the study were lactation number, change in BCS (determined according to Wildman et al., 1982) between calving and peak lactation (cutoff at $>0.5$ ), date of AI (summer or winter), and herd-period. Cyclicity before synchronization and AI, as determined by pedometry (Afimilk), was included in the model. Uterine health status postpartum, which was added to the model, included retained fetal membranes (for more than 24 
$\mathrm{h}$ after calving), endometritis (enlarged nonpregnant uterus with inflammation and purulent vaginal discharge), and pyometra (enlarged nonpregnant uterus with purulent content at least 30 to $40 \mathrm{~d}$ postpartum).

\section{Experiment 2: Study Design for the Management Approach}

This study was performed with cows assigned to uninfected or subclinical mastitis subgroups before AI. Data were collected from a single commercial herd from 2009 through 2011. Cows before first service were checked for presence of subclinical mastitis by SCC level before AI. For all cows, the SCC was determined in milk samples obtained in 2 or 3 (depending on duration of calving to first AI interval) consecutive monthly milk tests collected before AI. Cows with a SCC exceeding the threshold of 150,000 cells/mL of milk in all samples collected, were considered as subclinical mastitic cows (Lavon et al., 2011a). Cows with all samples less than 150,000 cells $/ \mathrm{mL}$ of milk were considered uninfected, and those with mixed values (above and below cutoff line) were not included in the study, as described above. Each group (uninfected and subclinical) was further divided randomly into 2 subgroups: single, routine AI (described below) following detection of estrus (single $\mathrm{AI}, \mathrm{n}=238$ ), or $2 \mathrm{AI}$, the first a routine procedure and the second performed $24 \mathrm{~h}$ later $(2 \mathrm{AI}, \mathrm{n}=117)$. Detection of estrus occurred trice daily before milking by a computerized pedometric system (Afimilk). Cows were inseminated once daily during the morning hours by an AI technician. Cows that were diagnosed as in estrus at the morning milking were AI on the same day, on average $4 \mathrm{~h}$ later. Cows that were detected to be in estrus at the noon or evening milking (or both) were AI the next morning, up to $20 \mathrm{~h}$ after detection of estrus. Thus, the single AI treatment and the first AI of the 2 AI treatment were performed 4 to $20 \mathrm{~h}$ after detection of estrus, and the second AI (in the 2 AI treatment) was performed 28 to $44 \mathrm{~h}$ after estrus was detected.

Four experimental groups were formed: uninfectedsingle AI $(\mathrm{n}=124)$, uninfected-2 AI $(\mathrm{n}=59)$, subclinical-single AI $(\mathrm{n}=114)$, and subclinical-2 AI $(\mathrm{n}=58)$. In the 2-AI groups, semen obtained from 2 different bulls was used for the first and second AI. Using 2 sires allowed the true sire to be determined later by DNA analysis. Earpiece skin samples were taken from the newborn calves for DNA analysis and compared with the DNA profiles of the sires used at BactoChem Laboratories (Ness-Ziona, Israel) according to procedures described in previous studies (Karniol et al., 2009; Stevanovic et al., 2010). All AI were performed by the same technician, and pregnancy was confirmed by uterine palpation per rectum 40 to $50 \mathrm{~d}$ after AI. Cows that exhibited estrus before being checked for pregnancy and those that were not diagnosed as pregnant were recorded as nonpregnant. Data were collected for first and second services.

\section{Data Analyses}

Experiments 1 and 2 were analyzed independently; no comparison was made between studies. A multivariable model was designed with a logistic model statement using the GLIMMIX procedure of SAS (version 9.2, SAS Institute Inc., Cary, NC), with insemination outcome as the dependent variable, as previously described (Lavon et al., 2011a). First AI CR in the hormonal approach (experiment 1), and CR of first and second services in the management approach (experiment 2) were calculated as number of pregnancies divided by number of AI.

In experiment 1 (hormonal approach), the entire data set $(\mathrm{n}=1,553 \mathrm{AI})$ was analyzed with the general form:

$$
\begin{gathered}
\mathrm{CR}=\text { intercept }+ \text { SCC group }+ \text { treat }+ \text { herd-period } \\
+ \text { season }+ \text { uterine disease }+ \text { parity }+ \text { BCS diff } \\
+ \text { cyclicity }+ \text { treat } \times \text { SCC group }+ \text { treat } \\
\times \text { uterine disease }+ \text { treat } \times \text { season }+ \text { treat } \times \text { parity } \\
+ \text { treat } \times \text { BCS diff }+ \text { parity } \times \text { SCC group }+ \text { treat } \\
\quad \times \text { SCC group } \times \text { parity }+ \text { error },
\end{gathered}
$$

where $\mathrm{CR}=\ln \mathrm{P} /(1-\mathrm{P}), \mathrm{P}=$ probability of pregnancy; $\mathrm{SCC}$ group $=$ uninfected or subclinical groups; treat $=$ AI following estrus or Ovsynch; herd-period $=3$ commercial dairy herds within period of insemination; uterine disease $=$ uterine health status postpartum; season $=\mathrm{AI}$ in summer and fall (July to October), or winter and spring (November to June); parity = first, second, third, and more lactations; BCS diff = change in BCS between calving and peak lactation; and cyclicity = cyclic, noncyclic, or unknown before synchronization and AI.

All variables were considered fixed effects. Milk yield and all of the third-degree interactions tested were found not to be significant and were therefore excluded from the final model.

In experiment 2 (management approach), the entire data set $(\mathrm{n}=355 \mathrm{AI})$ was analyzed with the general form:

$$
\begin{gathered}
\mathrm{CR}=\text { intercept }+\mathrm{SCC} \text { group }+ \text { treat }+ \text { season } \\
+ \text { uterine disease }+ \text { parity }+ \text { service number }+ \text { treat } \\
\times \text { SCC group }+ \text { treat } \times \text { uterine disease }+ \text { treat }
\end{gathered}
$$




$$
\begin{gathered}
\times \text { season }+ \text { treat } \times \text { parity }+ \text { treat } \times \text { BCS diff } \\
+ \text { parity } \times \text { SCC group }+ \text { treat } \times \text { SCC group } \\
\times \text { parity }+ \text { error },
\end{gathered}
$$

where $\mathrm{CR}=\ln \mathrm{P} /(1-\mathrm{P}), \mathrm{P}=$ probability of pregnancy; $\mathrm{SCC}$ group $=$ uninfected or subclinical groups; treat $=$ single AI or $2 \mathrm{AI}$; uterine disease = uterine health status postpartum; season $=\mathrm{AI}$ in summer and fall (July to October), or winter and spring (November to June); parity $=$ first, second, third, and above lactation; and service number $=$ first or second service. All variables were considered fixed effects.

Probability of conception for the level of a specific variable included in the 2 models was based on least squares means values. To compare levels within a variable, we ran the Bonferroni adjustment for multiple comparisons.

\section{RESULTS}

\section{Experiment 1: Hormonal Approach}

Irrespective of their effect on probability of conception, described in Table 1, none of the following factors differed among uninfected-E, uninfected-OVS, subclinical-E, and subclinical-OVS groups: parity (2.66 $\pm 0.1)$, BCS at calving $(3.31 \pm 0.02)$, BCS at peak lactation $(2.62 \pm 0.02)$, DIM at $\mathrm{AI}(97 \pm 1.3)$, and average percentage of postpartum uterine diseases in the 4 groups (47\%). Overall, probability of conception before association with health status tended to differ between cows inseminated following detected estrus or the OVS protocol $(P=0.105$; Table 1$)$. Moreover, subclinical mastitis tended to decrease the probability of conception relative to that of uninfected cows $(P=$ 0.093; Table 1). As expected, main effects of season, BCS difference, cyclicity, uterine disease, and herdperiod were significant, but their interactions with treatment were not. In contrast, a significant effect was noted for the treatment $\times \mathrm{SCC}$ group interaction $(P=$ 0.005). The subclinical-E treatment reduced the probability of conception compared with the uninfected-E group $(P=0.014$; Table 1$)$, whereas the OVS protocol abolished this reduction in the subclinical-OVS group. The subclinical-E cows had a $36.4 \%(-0.114 / 0.313$; LSM difference between subclinical-E and uninfected-E groups divided by LSM of the uninfected-E group) lower probability of conception than that of the uninfected-E group. In contrast, the subclinical-OVS group showed a $35.4 \%$ elevation in probability of conception compared with the subclinical-E group ( $-0.109 / 0.308$; LSM difference between subclinical-E and subclinical-OVS groups divided by LSM of the subclinical-OVS group).
Additional analysis based on Bonferroni adjustment for multiple comparisons indicated a tendency for the subclinical-E group to have a lower probability of conception than the subclinical-OVS group $(P=0.074)$, whereas the uninfected-OVS group did not differ in this respect from the subclinical-OVS group $(P=1.00)$. The actual mean $\mathrm{CR}$ for the 4 experimental groups are presented in Figure 1. Mean CR of uninfected-E, uninfected-OVS, and subclinical-OVS groups (40.5\%) was similarly greater by 14.1 percentage units than that of the subclinical-E group $(P<0.01)$.

In contrast to its positive effect in subclinical mastitic cows, multiple comparison analysis indicated that the uterine disease-OVS group did not have improved probability of conception compared with the uterine disease-E group $(P=1.00)$. The actual mean $\mathrm{CR}$ for the 4 experimental groups are presented in Figure 2.

\section{Experiment 2: Management Approach}

Analysis of the overall data set indicated that insemination of dairy cows twice, $24 \mathrm{~h}$ apart, did not improve overall probability of conception. In addition, probability of conception did not differ between subclinical mastitic cows inseminated once or twice (Table 2 ). The actual mean $\mathrm{CR}$ for the 4 experimental groups are presented in Figure 3. Additional analysis indicated no differences in CR associated with a 4 - to 20 -h interval between estrus detection and first AI, and a 28- to 44-h interval corresponding to second AI.

Comparison of the DNA of the newborns (delivered from 52 cows that conceived and calved out of 1212 -AI treatment cows; CR of $43 \%$ ) to that of the sires used (first or second $\mathrm{AI}$ ) of cows that were inseminated twice showed that most cows that calved $(49 / 52 ; 94 \%)$ conceived after the first AI (Table 3). Only 2/52 (4\%) cows conceived after the second AI. This proportion was not affected by health status.

\section{DISCUSSION}

This study examined 2 approaches to improve CR of subclinical mastitic cows: hormonal (experiment 1) and management (experiment 2). Results showed a substantial and significant improvement of CR by the OVS protocol, whereas the management approach had no effect on fertility. This study is the first to present a feasible and specific hormonal means for improving fertility in a designated subgroup of lactating cows exposed to a specific chronic pathogenic stress such as subclinical mastitis.

The main assumption of this study was that OVS would specifically improve conception in those subclinical mastitic cows that would otherwise exhibit delayed 


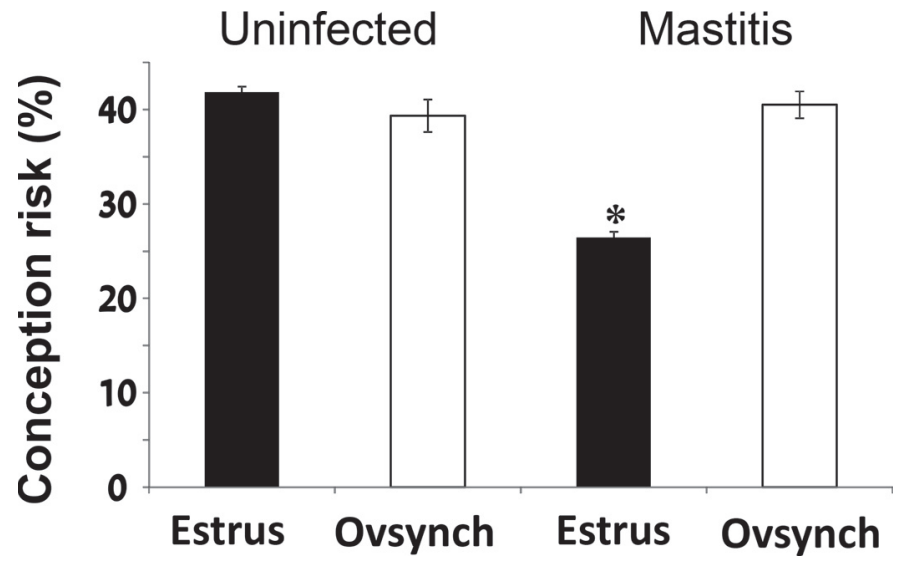

Figure 1. Effect of AI after Ovsynch or detected estrus on actual conception risk in uninfected and subclinical mastitic cows. Number of AI: uninfected-E $(\mathrm{n}=593)$, uninfected-OVS $(\mathrm{n}=572)$, subclinical-E $(\mathrm{n}=193)$, and subclinical-OVS $(\mathrm{n}=195)$. Data are presented as mean \pm SEM. ${ }^{*} P=0.005$, treatment $\times$ SCC group interaction. $\mathrm{E}=$ estrus; OVS $=$ Ovsynch.
Uninfected

Uterine disease

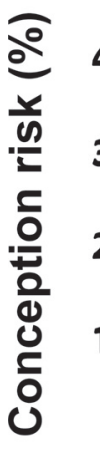

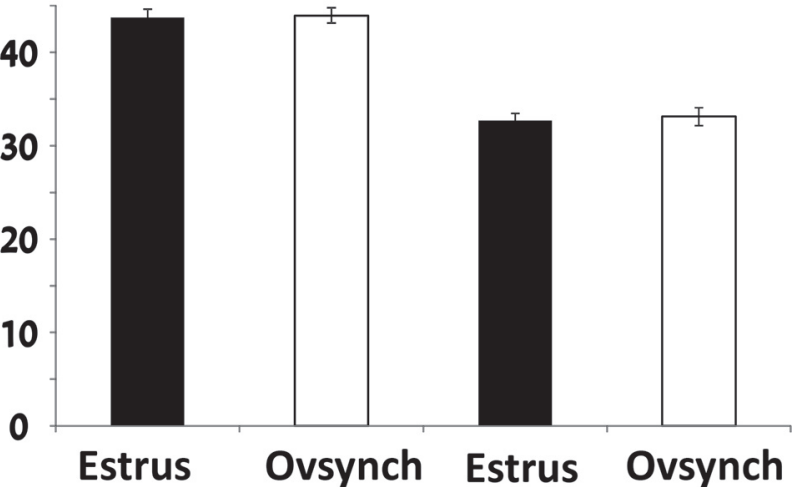

Figure 2. Effect of AI after Ovsynch or detected estrus on actual conception risk in uninfected cows and cows with uterine disorder postpartum. Number of AI: uninfected-E $(\mathrm{n}=382)$, uninfected-OVS $(\mathrm{n}=462)$, subclinical-E $(\mathrm{n}=404)$, and subclinical-OVS $(\mathrm{n}=305)$. Data are presented as mean $\pm \mathrm{SEM} . \mathrm{E}=$ estrus; OVS $=$ Ovsynch.

Table 1. The generalized mixed model used to estimate the effect of using the Ovsynch protocol on probability of conception in healthy and subclinical mastitic cows (experiment 1$)^{1}$

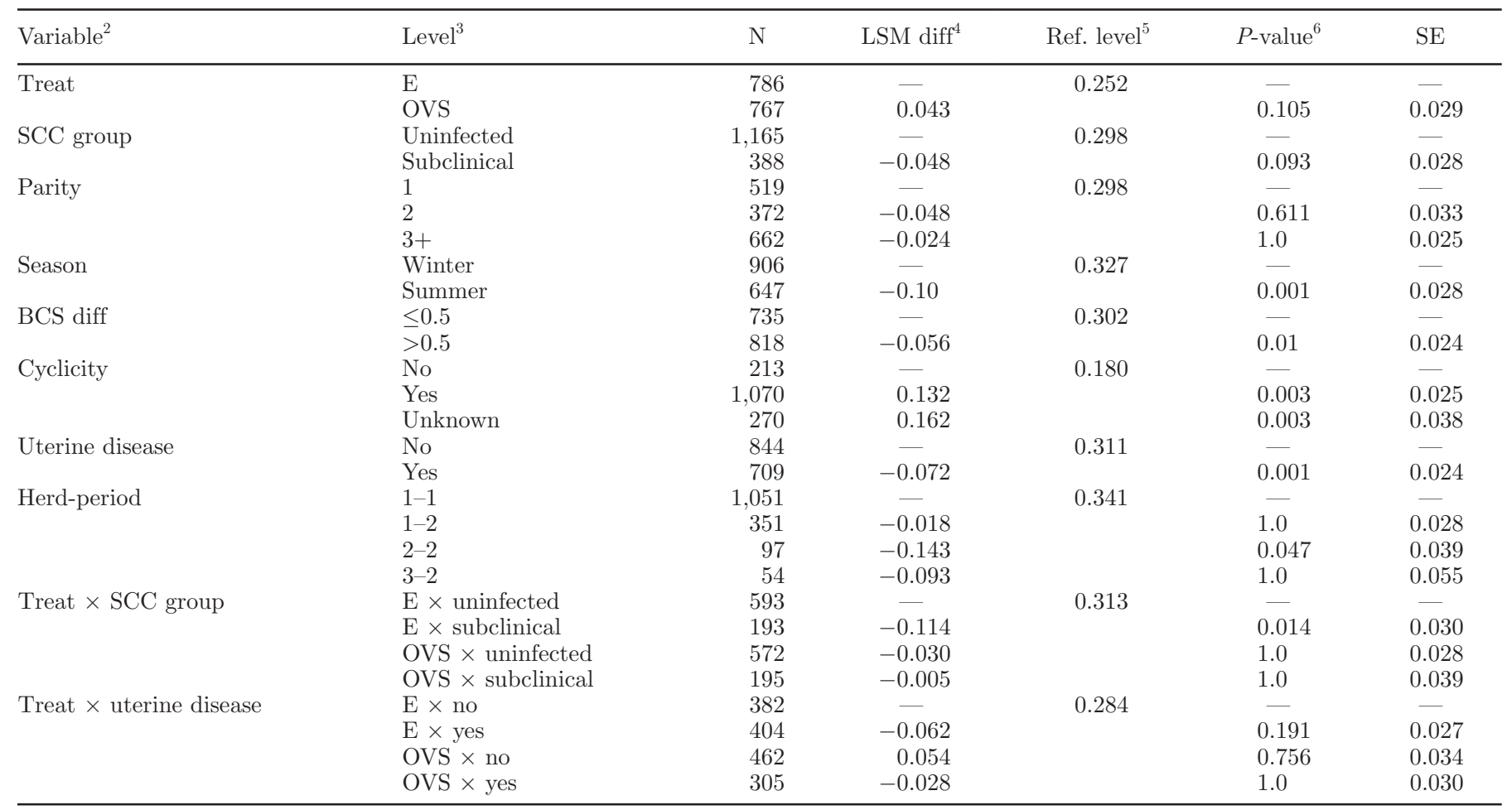

\footnotetext{
${ }^{1}$ Data consist of 1,553 AI from 3 herds in 2 time periods.

${ }^{2}$ Uninfected cows had SCC $<150,000$ cells $/ \mathrm{mL}$ in all milk tests before first AI; subclinical mastitic cows had SCC $>150,000$ cells $/ \mathrm{mL}$ in all milk tests before first AI; cyclicity = before synchronization and AI; herd-period $=3$ herds and 2 (early and late) periods.

${ }^{3} \mathrm{E}=\mathrm{AI}$ after estrus; OVS = AI after Ovsynch; BCS diff = change in body condition between calving and peak lactation.

${ }^{4}$ Differences in parameters least squares means (LSM diff) are deviations from the reference levels.

${ }^{5}$ Reference levels of the variables correspond to probabilities of conception of each variable.

${ }^{6}$ Adjusted by Bonferroni correction for multiple comparisons.
} 
Table 2. The generalized mixed model used to estimate the effect of insemination of dairy cows twice, $24 \mathrm{~h}$ apart, on probability of conception in healthy and subclinical mastitic cows (experiment 2$)^{1}$

\begin{tabular}{|c|c|c|c|c|c|c|}
\hline Variable & Level & $\mathrm{N}$ & $\mathrm{LSM}_{\operatorname{diff}}{ }^{2}$ & Ref. level $^{3}$ & $P$-value ${ }^{4}$ & SE \\
\hline Treat & Two AI & 117 & -0.014 & 0.340 & 0.837 & 0.056 \\
\hline \multirow[t]{3}{*}{ Parity } & 1 & 141 & - & \multirow[t]{3}{*}{0.351} & - & - \\
\hline & 2 & 69 & -0.066 & & 1.0 & 0.062 \\
\hline & $3+$ & 145 & 0.014 & & 1.0 & 0.047 \\
\hline \multirow[t]{2}{*}{ BCS diff } & $\leq 0.5$ & 236 & - & \multirow[t]{2}{*}{0.345} & - & - \\
\hline & $>0.5$ & 119 & -0.023 & & 0.704 & 0.048 \\
\hline \multirow[t]{2}{*}{ Uterine disease } & No & 196 & - & \multirow[t]{2}{*}{0.354} & - & - \\
\hline & Yes & 159 & -0.021 & & 0.344 & 0.038 \\
\hline \multirow[t]{2}{*}{ Service number } & First & 232 & - & \multirow[t]{2}{*}{0.330} & - & - \\
\hline & Second & 123 & 0.006 & & 0.898 & 0.047 \\
\hline Treat $\times$ SCC group & Single AI $\times$ uninfected & 124 & - & 0.372 & - & - \\
\hline
\end{tabular}

${ }^{1}$ Data consist of 355 AI from a single commercial dairy farm.

${ }^{2}$ Differences in least squares means of parameters (LSM diff) are deviations from the reference levels.

${ }^{3}$ Reference levels of the variables correspond to probabilities of conception of each variable.

${ }^{4}$ Adjusted by Bonferroni correction for multiple comparisons.

${ }^{5}$ Uninfected cows had $\mathrm{SCC}<150,000$ cells $/ \mathrm{mL}$ in all milk tests before first AI; subclinical mastitic cows had SCC $>150,000$ cells $/ \mathrm{mL}$ in all milk tests before first AI.

ovulation because of secretion of low (and delayed) preovulatory LH surge (Lavon et al., 2010). It is likely that the second dose of GnRH in the OVS protocol induced a normal LH surge and ovulation followed by timed AI at the optimal time. Importantly, the subgroup of about $30 \%$ of subclinical mastitic cows that will potentially exhibit delayed ovulation could not be identified

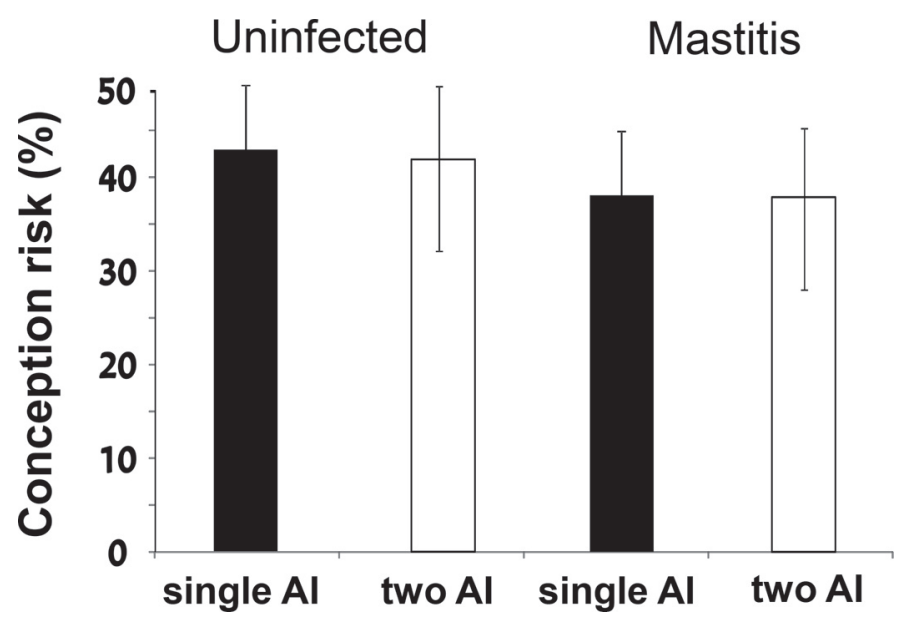

Figure 3. Effect of single AI or $2 \mathrm{AI}$ on actual conception risk in uninfected and subclinical mastitic cows. Number of AI: uninfectedsingle AI $(\mathrm{n}=124)$, uninfected-2 AI $(\mathrm{n}=59)$, subclinical-single AI $(\mathrm{n}=114)$, and subclinical-2 AI $(\mathrm{n}=58)$. Data are presented as mean \pm SEM. at present by practical means at the commercial farm level. This is because their follicular growth dynamics and size of the preovulatory follicle do not differ from those of the remaining $70 \%$ of mastitic cows that exhibit normal timing of ovulation (Lavon et al., 2010). Consequently, the entire subgroup of subclinical cows should be treated to achieve higher fertility.

Of particular importance is the finding that cows that had exhibited postpartum endometritis or retained placenta, which are also known to reduce fertility in cows, did not show improved CR with OVS. This lack of difference suggests that mammary and uterine diseases, considered to be the 2 major diseases of dairy cows, disrupt different reproductive mechanisms. Possible differences between the 2 diseases underlie their effects on ovulation: mastitis induces delayed ovulation (Lavon et al., 2010), whereas endometritis has been reported to cause anovulation (Williams et al., 2008). Another difference between the 2 diseases is that postpartum endometritis significantly delays resumption of cyclicity postpartum (Esslemont and Kossaibati, 2002; Sheldon et al., 2008), whereas mastitis showed a delay in onset of first estrus and resumption of cyclicity of only 2 and 6 d, respectively (Y. Zehavi, Hebrew University, Rehovot, Israel, and D. Wolfenson, unpublished data; Huszenicza et al., 2005). Thus, the low fertility of cows with postpartum uterine diseases may be associated with delayed postpartum cyclicity (Vercouteren et al., 2015). Fur- 
Table 3. Distribution of conceiving bull semen in cows receiving two $\mathrm{AI}^{1} 24 \mathrm{~h}$ apart (experiment 2) that conceived and calved, based on comparative DNA analysis of newborns and sires used

\begin{tabular}{lcc}
\hline Variable & First AI & Second AI \\
\hline Cows conceived and calved, no./total (\%) $^{2}$ & $49 / 52(94)$ & $2 / 52(4)$ \\
Overall $^{2}$ & $25 / 26(96)$ & $1 / 26(4)$ \\
Uninfected $_{\text {Subclinical }}^{3}$ & $24 / 26(92)$ & $1 / 26(4)$ \\
\hline
\end{tabular}

${ }^{1}$ First and second AI were performed 4 to $20 \mathrm{~h}$ and 28 to $44 \mathrm{~h}$ after first estrus detected by pedometry.

${ }^{2} 52$ of $121(43 \%)$ two-AI treatment cows conceived and calved.

${ }^{3}$ In one cow, the conceiving bull was not identified.

thermore, others have found an association between uterine diseases and abnormal progesterone profiles related to cystic ovaries or prolonged luteal phases (Opsomer et al., 2000; Royal et al., 2000), whereas subclinical mastitis-induced poor fertility is associated with failures of the preovulatory follicle and enclosed oocyte (Roth et al., 2013; Asaf et al., 2014; Furman et al., 2014), including delayed ovulation, which is corrected by the OVS procedure, as shown here.

The study emphasizes the notion that designated treatments should be applied to subgroups of cows subjected to specific pathogenic stresses, such as subclinical mastitis, to improve their fertility. Similar to the findings presented here, it has been recently shown that heat-stressed cows in the summer with low BCS, but not those with high BCS, respond positively to the addition of exogenous progesterone post AI (Friedman et al., 2012). This contrasts with the previous approach of applying a single treatment to the whole herd. Treating uninfected cows is not justified, particularly today when designated subgroups can be easily sorted and treated in modern, computerized herds.

The management approach of 2 AI $24 \mathrm{~h}$ apart failed to improve fertility of subclinical mastitic cows. Our hypothesis was that a second AI performed $24 \mathrm{~h}$ after the first routine AI would better suit the timing of ovulation in cows exhibiting delayed ovulation, consequently leading to improved CR. This was based on our previous study in which an average estrus-to-ovulation interval of $56 \mathrm{~h}$ was recorded in cows with delayed ovulation, compared with $28 \mathrm{~h}$ in cows with normal timing of ovulation (Lavon et al., 2010). A possible reason for the lack of improvement in fertility could be related to the likely association of low preovulatory LH surge with not only delayed ovulation but also disruption of oocyte maturation (Westergaard et al., 2000). Furthermore, low magnitude of LH surge has been shown to be associated with impaired luteinization of the CL and low circulating progesterone postovulation and insemination (Zelinski-Wooten et al., 1997; Bloch et al., 2006), which is also associated with low CR (Friedman et al., 2012).
In the present study, most of the twice-inseminated cows that conceived and calved $(\mathrm{CR}=43 \%)$ conceived after the first AI (96\%; irrespective of their health status). This is not surprising because the large interval (28-44 h) between first detection of estrus and second AI drastically lowers the chances of conception (Dransfield et al., 1998) among cows that ovulate normally.

In conclusion, the OVS protocol seems to be an efficient treatment for improving the fertility of cows with subclinical mastitis, likely due to the "corrected" timing of ovulation in cows that would otherwise exhibit delayed ovulation. Ovsynch did not improve the fertility of cows diagnosed with uterine disease postpartum. A management approach based on performing an additional AI $24 \mathrm{~h}$ after the first, regular AI failed to improve conception, which is likely to be related to the association of low preovulatory LH surge with not only delayed ovulation but also impairment of oocyte competence. The study emphasizes the need to provide designated treatments to specific groups of cows as a strategy to improve fertility of dairy cows.

\section{ACKNOWLEDGMENTS}

The authors thank the managers of the dairy herds that participated in the study for their valuable help and cooperation in performing the experiments: Y. Rotem, D. Sivan, O. Snir, A. Zaks, H. Zaks, and A. Zukerman. The study was supported by a grant from the Israeli Dairy Board \#820-271 (Yehud-Monoson).

\section{REFERENCES}

Asaf, S., G. Leitner, O. Furman, Y. Lavon, D. Kalo, D. Wolfenson, and Z. Roth. 2014. Effects of Escherichia coli and Staphylococcus aureus-induced mastitis in lactating cows on oocyte developmental competence. Reproduction 147:33-43.

Bloch, A., Y. Folman, M. Kaim, Z. Roth, R. Braw-Tal, and D. Wolfenson. 2006. Endocrine alterations associated with extended time interval between estrus and ovulation in high-yield dairy cows. J. Dairy Sci. 89:4694-4702.

Djabri, B., N. Bareille, F. Beaudeau, and H. Seegers. 2002. Quarter milk somatic cell count in infected dairy cows: A meta-analysis. Vet. Res. 33:335-357. 
Dransfield, M. B., R. L. Nebel, R. E. Pearson, and L. D. Warnick. 1998. Timing of insemination for dairy cows identified in estrus by a radiotelemetric estrus detection system. J. Dairy Sci. 81:18741882 .

Esslemont, D., and M. A. Kossaibati. 2002. The Cost of Poor Fertility and Disease in UK Dairy Herds. Intervet UK Ltd., Milton Keynes, UK.

Friedman, E., Z. Roth, H. Voet, Y. Lavon, and D. Wolfenson. 2012. Progesterone supplementation post insemination improves fertility of cooled dairy cows during the summer. J. Dairy Sci. 95:30923099 .

Furman, O., G. Leitner, Z. Roth, Y. Lavon, S. Jacoby, and D. Wolfenson. 2014. Experimental model of toxin-induced subclinical mastitis and its effect on disruption of follicular function in cows. Theriogenology 82:1165-1172.

Halasa, T., K. Huijps, O. Osteras, and H. Hogeveenb. 2007. Economic effects of bovine mastitis and mastitis management: A review. Vet. Q. 29:18-31.

Hertl, J. A., Y. T. Grohn, J. D. Leach, D. Bar, G. J. Bennett, R. N. Gonzalez, B. J. Rauch, F. L. Welcome, L. W. Tauer, and Y. H. Schukken. 2010. Effects of clinical mastitis caused by grampositive and gram-negative bacteria and other organisms on the probability of conception in New York State Holstein dairy cows. J. Dairy Sci. 93:1551-1560.

Hudson, C. D., A. J. Bradley, J. E. Breen, and M. J. Green. 2012. Associations between udder health and reproductive performance in United Kingdom dairy cows. J. Dairy Sci. 95:3683-3697.

Huszenicza, G., S. Jánosi, M. Kulcsár, P. Kóródi, J. Reiczigel, L. Kátai, A. R. Peters, and F. De Rensis. 2005. Effects of clinical mastitis on ovarian function in post-partum dairy cows. Reprod. Domest. Anim. 40:199-204.

Karniol, B., A. Shirak, E. Baruch, C. Singrün, A. Tal, A. Cahana, M. Kam, Y. Skalski, G. Brem, J. I. Weller, M. Ron, and E. Seroussi. 2009. Development of a 25-plex SNP assay for traceability in cattle. Anim. Genet. 40:353-356.

Lavon, Y., E. Ezra, G. Leitner, and D. Wolfenson. 2011a. Association of conception rate with pattern and level of somatic cell count elevation relative to time of insemination in dairy cows. J. Dairy Sci. 94:4538-4545.

Lavon, Y., G. Leitner, E. Klipper, U. Moallem, R. Meidan, and D. Wolfenson. 2011b. Subclinical, chronic intramammary infection lowers steroid concentrations and gene expression in bovine preovulatory follicles. Domest. Anim. Endocrinol. 40:98-109.

Lavon, Y., G. Leitner, H. Voet, and D. Wolfenson. 2010. Naturally occurring mastitis effects on timing of ovulation, steroid and gonadotrophic hormone concentrations, and follicular and luteal growth in cows. J. Dairy Sci. 93:911-921.

Losinger, W. C. 2005. Economic impacts of reduced milk production associated with an increase in bulk-tank somatic cell count on US dairies. J. Am. Vet. Med. Assoc. 226:1652-1658.

Opsomer, G., Y. T. Grohn, J. Hertl, M. Coryn, H. Deluyker, and A. de Kruif. 2000. Risk factors for postpartum ovarian dysfunction in high producing dairy cows in Belgium: A field study. Theriogenology $53: 841-857$.

Ramírez, N. F., G. Keefe, I. Dohoo, J. Sánchez, O. Arroyave, J. Cerón, M. Jaramillo, and L. G. Palacio. 2014. Herd- and cow-level risk factors associated with subclinical mastitis in dairy farms from the High Plains of the northern Antioquia, Colombia. J. Dairy Sci. 97:4141-4150.

Roth, Z., A. Dvir, D. Kalo, Y. Lavon, O. Krifucks, D. Wolfenson, and G. Leitner. 2013. Naturally occurring mastitis disrupts developmental competence of bovine oocytes. J. Dairy Sci. 96:6499-6505.

Royal, M., G. E. Mann, and A. P. Flint. 2000. Strategies for reversing the trend towards subfertility in dairy cattle. Vet. J. 160:53-60.

Santos, J. E., R. L. Cerri, M. A. Ballou, G. E. Higginbotham, and J. H. Kirk. 2004. Effect of timing of first clinical mastitis occurrence on lactational and reproductive performance of Holstein dairy cows. Anim. Reprod. Sci. 80:31-45.

Schrick, F. N., M. E. Hockett, A. M. Saxton, M. J. Lewis, H. H Dowlen, and S. P. Oliver. 2001. Influence of subclinical mastitis during early lactation on reproductive parameters. J. Dairy Sci. 84:1407-1412.

Sheldon, I. M., E. J. Williams, N. A. Miller, D. M. Nash, and S. Herath. 2008. Uterine diseases in cattle after parturition. Vet. J. 176:115-121

Stevanovic, J., Z. Stanimirovic, V. Dimitrijevic, and M. Maletic. 2010. Evaluation of 11 microsatellite loci for their use in paternity testing in Yugoslav Pied cattle (YU Simmental cattle). Czech J. Anim. Sci. 55:221-226.

Vercouteren, M. M., J. H. Bittar, P. J. Pinedo, C. A. Risco, J. E. Santos, A. Vieira-Neto, and K. N. Galvão. 2015. Factors associated with early cyclicity in postpartum dairy cows. J. Dairy Sci. 98:229-239.

Westergaard, L. G., S. B. Laursen, and C. Y. Andersen. 2000. Increased risk of early pregnancy loss by profound suppression of luteinizing hormone during ovarian stimulation in normogonadotrophic women undergoing assisted reproduction. Hum. Reprod. 15:1003-1008.

Wildman, E., G. M. Jones, P. E. Wagner, H. F. Troutt, and T. N. Lesch. 1982. A dairy cow body condition scoring system and its relationship to selected production characteristics. J. Dairy Sci. 65:495-501.

Williams, E. J., K. Sibley, A. N. Miller, E. A. Lane, J. Fishwick, D. M. Nash, S. Herath, G. C. England, H. Dobson, and I. M. Sheldon. 2008. The effect of Escherichia coli lipopolysaccharide and tumour necrosis factor alpha on ovarian function. Am. J. Reprod. Immunol. 60:462-473

Zelinski-Wooten, M. B., J. S. Hutchinson, I. Trinchard-Lugan, D. L. Hess, D. P. Wolf, and R. L. Stouffer. 1997. Initiation of periovulatory events in gonadotrophin-stimulated macaques with varying doses of recombinant human chorionic gonadotrophin. Hum. Reprod. 12:1877-1885. 